\title{
B103 画像勾配を用いた高精度サブピクセル解析法
}

\author{
杉井 康彦○ (東京大学), 西尾 茂 (神戸商船大学) \\ 奥野 武俊 (大阪府立大学), 岡本 孝司 (東京大学)
}

Accurate Sub-pixel Analysis on PIV using Gradient Method

\author{
Yasuhiko SUGII, Shigeru NISHIO, \\ Taketoshi OKUNO and Koji OKAMOTO
}

\begin{abstract}
In order to improve the dynamic range, spatial resolution and measurement accuracy, a number of iterative methods have been proposed. In these methods, the three-point Gaussian peak fit of correlation value is usually used for a sub-pixel analysis. However, it is reported that the root-mean-square (RMS) error is no less than 0.1 pixels because of simple courve fitting concept, and that it requires high particle concentration or the large correlation window.

The authors have proposed the high-resolution PIV technique based on the crosscorrelation and the gradient method. In this paper, the sub-pixel displacement in the proposed technique is obtained using the spatio-temporal derivative method instead of the three-point Gaussian peak fit. The error of the proposed technique is analytically evaluated as the function of sub-pixel displacement, the particle image density and the out-of-plane displacement using Monte Carlo simulations. It is confirmed that the present method shows the higher performance both on the accuracy and the special resolution than the Gaussian fit method, and its RMS error is in the order of 1/100 pixels.
\end{abstract}

Keywords: PIV, High-Resolution Method, Gradient Method, Sub-pixel Analysis, MonteCarlo simulations

\section{1. 緒言}

可視化画像を使って非接触で流れ場の速度分布を計測 する手法の一つである PIV(Particle Image Velocimetry)は, 広い研究分野で用いられるようになっ ている ${ }^{1)}$. 代表的な手法である相関法では, 画像の相関 係数からトレーサ群の移動量が求められ, 沉用的な手法 として広く用いられている。近年，得られる速度分布の 空間解像度を上げるために, 階層的に相関法を繰り返す 高解像度計測法が提案されている ${ }^{2)}$. また, 得られる 速度べクトルが画素単位であるため, 画素単位以下の移 動量を求めるサブピクセル解析手法が提案されている. しかしながら，相関係数をガウス関数などを用いて近似 するため, 計測精度が 0.1[pixel]程度に限られており， 高い粒子密度が必要であることが報告されている (i).一方, 画像の Lagrange 微分を用いて定式化された時 空間微分法は, 元来オプティカルフローの検出のために
開発され，微小な画像の移動量の計測に適している778) 9). この手法は勾配法とも呼ばれ, 高い空間解像度と微 小な移動量を検出できるという利点を生かして, 壁面摩 擦応力の計測などにも適用されている 10)11).

著者らは, 階層的に相関法を用いてダイナミックレン ジを拡大するとともに, サブピクセル解析に時空間微分 法を用いる新しい高精度な高解像度画像計測法を提案し, 振動翼周りの流れの可視化画像に適用した 12) 13). 本報 告では, 提案している高解像度画像計測法において, 時 空間微分法を用いたサブピクセル解析手法を示すと共に, モンテカルロシュミレーションにより計測精度を検討す る.

\section{2. 高解像度画像計測法}

\section{1 階層的相関法}

相関法では連続する 2 枚の画像の相関係数を求め, その最大值を取る位置から移動量が求まる。しかしなが ら, 小さな相関領域を用いた場合には, 情報量が不足す 
るために多数の相関係数のピークが現れ，過誤ベクトル が発生する事が知られている。そのため, 通常 $32 \times 32$ [pixel $\times$ pixel]程度の大きな領域が用いられており， 得られる速度分布の空間解像度が悪くなるなどの問題が ある。そのため, 相関領域を小さくしながら相関法を繰 り返し適用する階層的相関法が提案されている.

階層的相関法では, まず通常の大きな相関領域の相関 法により大まかな速度分布を求め, 得られた速度分布を 用いて探索範囲を限定した上で, 相関領域を小さくして 再び相関法を適用する。これを繰り返すことにより，非 常に小さな相関領域を用いた高解像度な速度分布が得ら れる，得られる速度べクトルは画素単位であるため, 通 常は相関係数の関数近似を行って, 画素単位以下の移動 量を求めるいわゆるサブピクセル解析が行われる，相関 係数をガウス関数で近似するガウシアンフィットでは, 移動量 $\delta$ は,

$$
\delta=\frac{1}{2} \frac{\ln R(\xi-1)-\ln R(\xi+1)}{\ln R(\xi-1)+\ln R(\xi+1)-2 \ln R(\xi)}
$$

により与えられる。ここで, $\xi$ は一次元の場合の相関倸 数 $R(\xi)$ が最大值を与える画素単位の位置である. しか しながら，この方法は 0.1[pixel]程度の精度しかなく， 高い粒子密度が必要なために大きな相関領域が用いる必 要があるなどの問題がある，そのため，小さな解析領域 で高精度な計測ができる手法が期待されている.

\section{2 高解像度画像計測法}

著者らが提案している高解像度画像計測法では, 探索 領域などの解析パラメ夕を最適化しながら階層的相関法 を適用し, サブピクセル解析として時空間微分法を用い る. 本手法のサブピクセル解析として用いる時空間微分 法は, 輝度の Lagrange 微分を用いた拘束式で表され, 微小な移動量を高精度に求めることができる手法として 知られている。しかしながら，大きな移動量の領域では 誤差が大きくなるなどの問題が残されていた。本手法で は, 階層的相関法により画素単位の移動量 $(\Delta x, \Delta y)$ が低 誤対応率で求められるため, サブピクセル解析に時空間 微分法を適用して画素単位以下の移動量 $(\delta x, \delta y)$ を高精 度に求めることができる。

Fig.1に示すように, 時刻 $t-\Delta t$ から $t+\Delta t$ の間に $(x-\delta x, y-\delta y)$ から $(x+\delta x, y+\delta y)$ に粒子像が移動した 時, 輝度が Taylor 展開できると仮定すると, (2)式の時 空間微分法の拘束式が得られる.

$$
\frac{\partial f}{\partial t}+u \frac{\partial f}{\partial x}+v \frac{\partial f}{\partial y}=\lim _{\Delta t \rightarrow 0} \frac{\Delta g(x, y, t, \Delta t)}{2 \Delta t}
$$

ここで, $u=\lim _{\Delta t \rightarrow 0} \delta x / \Delta t, v=\lim _{\Delta t \rightarrow 0} \delta y / \Delta t, g$ はバッ クグランドの輝度分布である.

(2)式には 2 変数 $(u, v)$ が含まれるため, 微小領域におい て右辺が十分に小さく, $(u, v)$ が一定とみなして最小二 乗法を適用し，残差 $\sum_{A}\left(\frac{\partial f}{\partial t}+u \frac{\partial f}{\partial x}+u \frac{\partial f}{\partial y}\right)^{2}$ を最小にす る速度 $(u, v)$ を求める。すなおち, 速度 $(u, v)$ は,

$$
\left(\begin{array}{cc}
\sum \frac{\partial f}{\partial x} & \sum \frac{\partial f}{\partial x} \frac{\partial f}{\partial y} \\
\sum \frac{\partial f}{\partial x} \frac{\partial f}{\partial y} & \sum \frac{\partial f}{\partial y}
\end{array}\right)\left(\begin{array}{l}
u \\
v
\end{array}\right)=-\left(\begin{array}{l}
\sum \frac{\partial f}{\partial x} \frac{\partial f}{\partial t} \\
\sum \frac{\partial f}{\partial y} \frac{\partial f}{\partial t}
\end{array}\right)
$$

\section{により得られる。}

本手法では，階層的相関法によって得られた移動量 $(\Delta x, \Delta y)$ を用いて, 異なる位置での輝度の時間変化によ り微小な移動量 $(\delta x, \delta y)$ を求める。すなわち, 1 時刻目 の画像 $f(x, y, t-\Delta t)$ と 2 時刻目の画像 $f(x+\Delta x, y+\Delta y, t+\Delta t) に$, 上述の方法に適用し, サブ ピクセル解析を行う．Fig. 2 に, 本手法の解析手順を示 す.

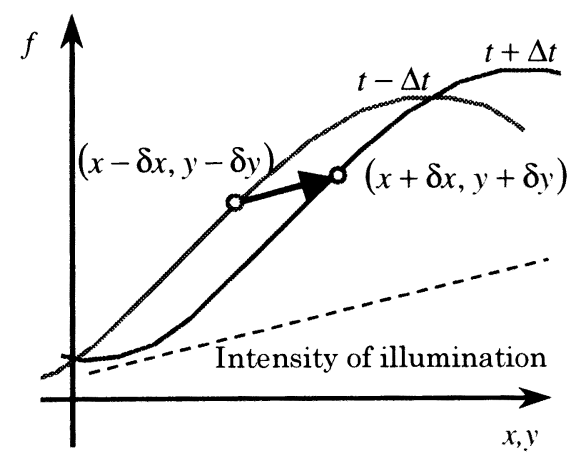

Fig.1 Principle of the spatio-temporal derivative method

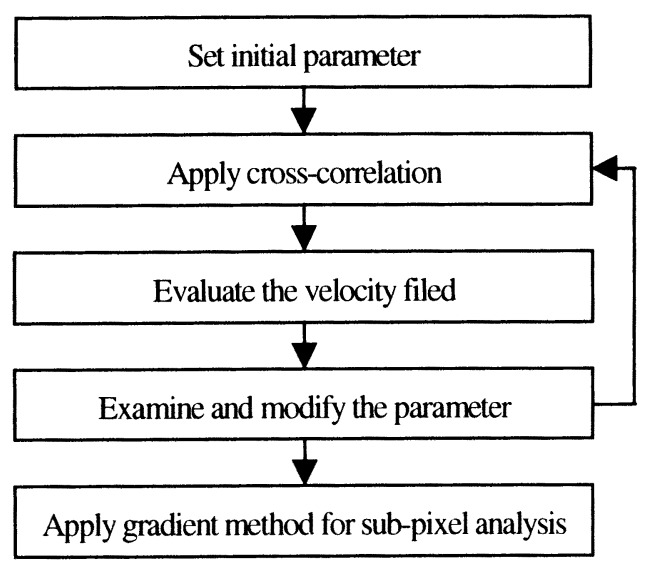

Fig.2 Flow diagram of the present method 


\section{3. 誤差解析}

前節で示した高解像度画像計測法の特性を，モンテカ ルロシミュレーションによって調べた。移動量, 粒子径, 粒子密度などのパラメ夕を変化させて, 粒子画像をコン ピュー夕により作成する．粒子の輝度分布をガウス分布 で直接与え, 各粒子を移動させて時系列の画像データを 作成する，画像の大きさは $256 \times 256$ [pixel $\times$ pixel], 256 階 調である．階層的相関法により画素単位の移動量が高い 対応率で求めることができるので, ここでは, サブピク セル精度についてのみ検討を行う。

\section{1 粒子密度}

Fig.3に解析領域内の粒子密度 $N_{I}$ による誤差を示す. 図中の粒子密度 $C$, 解析領域内の粒子数 $N_{I}$ は,

$$
\begin{aligned}
& C=\frac{N}{V} \Delta z_{0} \\
& N_{I}=C D_{I}{ }^{2}
\end{aligned}
$$

である.ここで， $N$ は粒子数， $V$ は可視化領域の大き さ, $\Delta z_{0}$ はレーザーシート光の厚さ， $D_{I}$ は解析領域の 大きさである。

解析条件は, $d_{i}=5.0[\mathrm{pixel}], D_{I}=33[\mathrm{pixel}]$ とした。 ここで示す誤差の指標は, 移動量が $0.0 \sim 0.5$ [pixel] 範 囲における誤差の平均值を用いている。 ガウシアンフィ ットでは, 粒子密度が大きくなるに従って誤差が増加し, $N_{I}<10$ でその増加率が大きくなる.つまり, 高い粒子 密度が必要であることを示している。一方, 本手法では $N_{I}>4$ で誤差はほほ一定值となり, 解析領域内に 2,3 個の粒子でも十分に小さな値となる。これは, 解析領域 を小さくでき, 高い空間解像度の速度分布を求めること ができることを意味する。

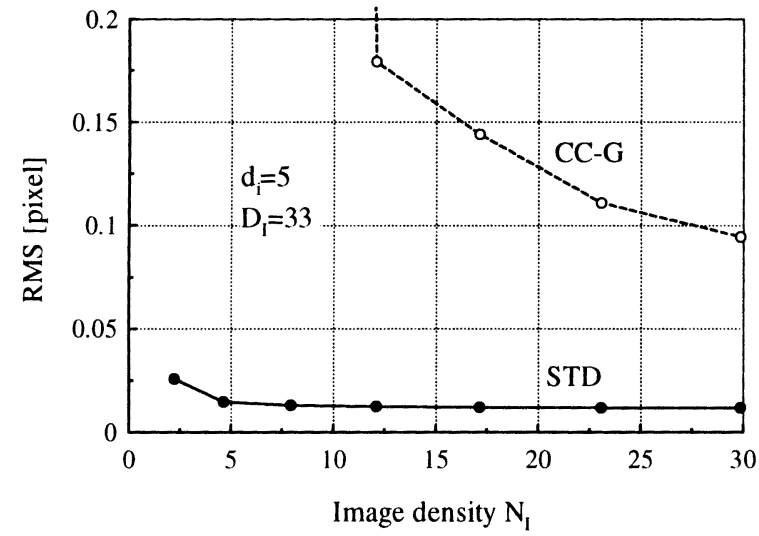

Fig.3 Measurement uncertainty RMS error in spatio-temporal derivative method (STD) and three-point Gaussian fit based on crosscorrelation (CC-G) as a function of the image density per interrogation window, $N_{I}$

\section{2 サブピクセル精度}

前節では，粒子密度の誤差に対する影響を検討したが, ここでは画素単位以下の移動量の精度を詳細に調べる。

Fig.4 にサブピクセル精度を示す. 前節と同じ粒子径 $d_{i}=5.0[\mathrm{pixel}] て ゙$, 粒子密度 $C=0.016,0.027,0.049$ と変 化させた，前節で示したように，ガウシアンフィットは 高い粒子密度が必要なので解析領域の大きさ $D_{I}=33$ [pixel] とし, 本手法では $D_{I}=13$ [pixel] とする. そのため, 同じ画像データであるが，解析領域の大きさ が異なるために，ガウシアンフィットでは $N_{I}=17.9$, $29.9,53.8$, 本手法では $N_{I}=2.8,4.6,8.3$ となる. ガウ シアンフィットでは移動量によらず, 誤差がほぼ一定值 をとり， $N_{I}$ が大きくなるにつれて誤差が減少し， $N_{I}=53.8$ の時に約 0.07 [pixel] となる. 本手法による誤 差は, 解析領域の大きさが小さく, 粒子密度も低いにも かかわらず，ガウシアンフィットより小さい.また，移 動量にほほ比例した值をとり, 誤差は粒子密度の影響が 無く，小さな解析領域でも精度を保つことが確認でき る.

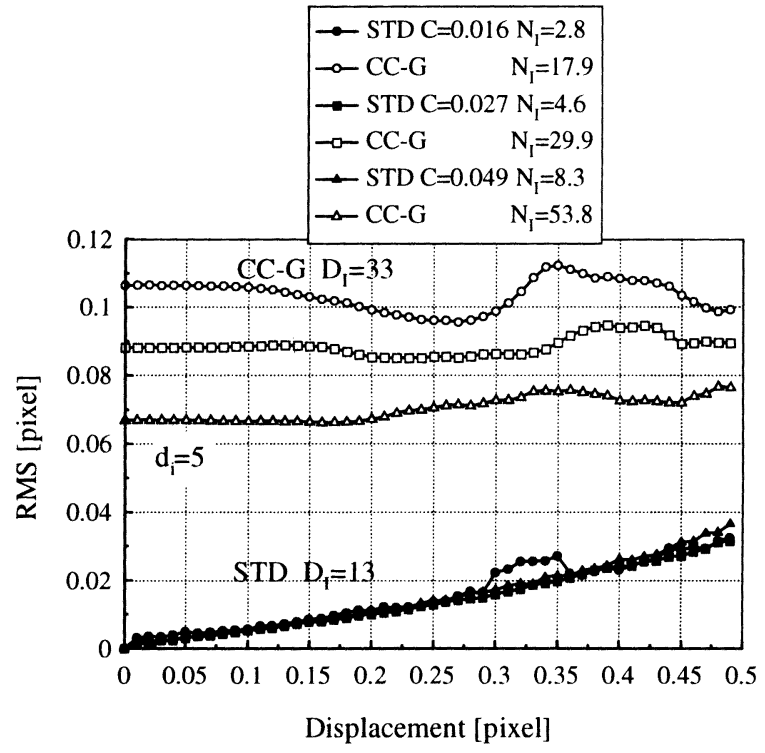

Fig.4 Measurement RMS as a function of subpixel displacement

\section{3 面外速度}

通常, PIV ではレーザシート光により可視化した流れ 場を 1 台のカメラで撮影して，二次元速度場が求められ ている.しかしながら, 計測対象が三次元流であること が多いので，シート光に垂直な運動による影響を検討す る必要がある．Fig.5 に面外速度 $W$ による誤差の変化を 示す。面外速度 $W$ は, 


$$
W=\frac{w}{\Delta z_{0}} \Delta t
$$

である。ここで， $w$ は速度のシート光に垂直な成分で あり，シート光の輝度分布はガウス分布である．解析条 件として前節と同様に粒子径 $d_{i}=5.0[\mathrm{pixel}]$, 粒子密度 $C=0.027$, ガウシアンフィットでは解析領域の大きさ $D_{I}=33[\mathrm{pixel}], N_{I}=29.9$ であり, 本手法の解析領域の 大きさ $D_{I}=13 \sim 33[\mathrm{pixel}], N_{I}=4.6 \sim 29.9$ と変化させ た。ガウシアンフィットの誤差は, 面外速度 $W$ が大き くなるにつれて増加する. 本手法の誤差も同様な傾向で あるが，粒子密度による影響が大きいことがわかる．本 手法では輝度が時間とともに変化しないと仮定している ために，面外方向への運動による輝度の変化が，精度に 大きく影響すると思われる。しかしながら， $N_{I}>17$ の 場合にはガウシアンフィットより誤差は小さい.

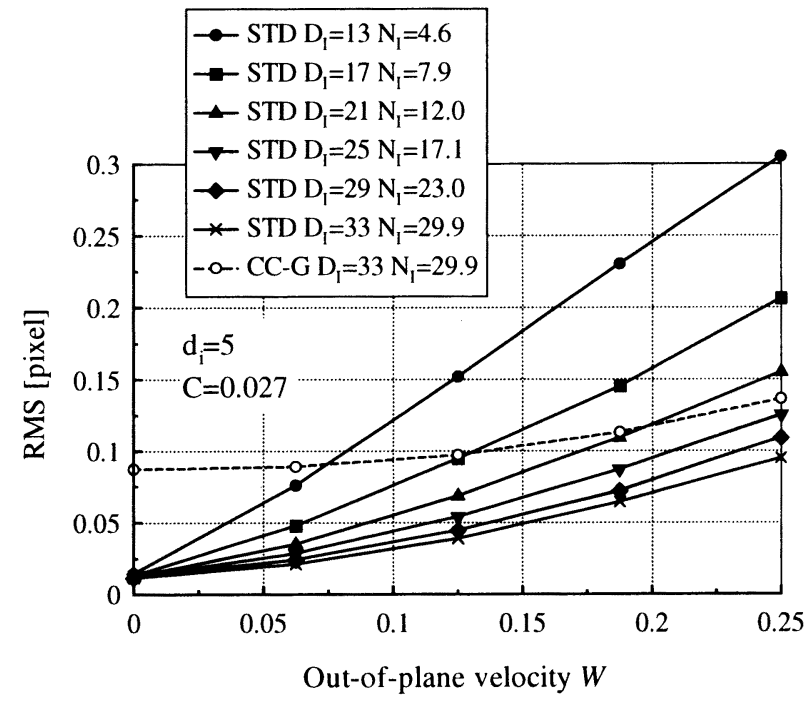

Fig.5 Measurement RMS error as a function of out-of-plane velocity, $W$

\section{4. 結言}

階層的相関法と時空間微分法を用いた高解像度画像計 測法におけるサブピクセル解析手法を詳細に示し，その 計測精度をモンテカルロシミュレーションを用いて検討 した。精度の検討をサブピクセルの移動量, 粒子密度, 面外速度を変化させて作成した粒子画像に適用して調へ たが，ガウシアンフィットが 0.1 [pixel]の精度であるに 対し, 本手法は 0.01[pixel]の精度であり，低い粒子密 度でも高精度を保つことができることが確認できた。こ れは，非常に小さな $7 \times 7$ [pixel×pixel]程度の解析領域を
用いることができ，高い空間解像度の速度分布を得る事 ができることを意味している。これにより，本手法が従 来の方法では得られなかったサブピクセル精度を高い空 間解像度で得ることができるようになった。しかしなが ら，バックグランドなどによる輝度の時間変化に弱く, 面外速度の影響が大きいことなども確認され広い分野で の計測には，いくつかの改善点が残されている.

\section{参 考文 献}

1) Raffel, M., Willert, C. E. and Kompenhans, J.: Particle image velocimetry Springer (1998).

2) Westerweel, J., Dabiri, D. and Gharib, M.: The effect of a discrete window offset on the accuracy of crosscorrelation analysis of digital PIV recordings, Exp. Fluids, Vol.23 (1997) pp.20-28.

3) Hart, D. P.: Super-resolution PIV by recursive localcorrelation, Proceedings of VSJ-SPIE98 (1998) AB149.

4) Scarano, F. and Riethmuller, M. L.: Interactive multigrid approach in PIV image processing, Exp. Fluids, Vol.26, (1999) pp.513-523

5) Keane, R. D. and Adrian, R. J.: Optimization of particle image velocimeters. Part 1 double pulsed system, Meas. Sci. Technol., Vol.1 (1990) pp.1202-1215.

6) Westerweel, J. M.: Theoretical analysis of the measurement precision and reliabillity in PIV Proceedings of the third International Workshop on PIV'99, (1999) pp.9-14.

7) Horn, B. K. P. and Schunk, B. G. : Determining optical flow Artificial Intelligence, Vol.17 (1981) pp.185-203.

8) Hildreth, E. C.: Computation Underlying the Measurement of visual motion, Artificial Intelligence, Vol.23 (1984) pp.309-54.

9）安藤繁：画像の時空間微分を用いた速度べクトル分布計 測システム, 計測自動制御学会論文集, Vol.22, No.12 (1986) pp.1330-1336.

10) 奥野武俊，中岡淳：可視化画像の時空間微分を利用した 流場の画像計測, 関西造船協会誌, No.215 (1991) pp.6974 .

11) Okuno, T.: Image measurement by means of spatiotemporal derivative method, Proceedings of the International Workshop on PIV'95-Fukui (1995) pp.167173.

12）西尾茂，中村研，奥野武俊，杉井康彦：多関節翼まわり の流れの可視化（第 3 報）一運動モードの検討一, 可視 化情報学会誌 Vol.19, Suppl., No.2 (1999) pp.133-136。

13) 杉井康彦, 奥野武俊, 西尾茂：相関法と時空間微分法を 用いた高解像度画像計測法, 関西造船協会春季講演会論 文集 (2000) pp.143-146. 